\title{
Apropos "Dengue virus identification by transmission electron microscopy and molecular methods in fatal dengue hemorrhagic fever"
}

\author{
S. C. Arya $\cdot$ N. Agarwal
}

Received: 24 November 2012/ Accepted: 26 December 2012/Published online: 18 January 2013

(C) Springer-Verlag Berlin Heidelberg 2013

\section{To the Editor}

We compliment the investigators from Havana, Cuba for their molecular, histological, and electron microscopy investigations of the postmortem tissues from a fatal case of dengue hemorrhagic fever (DHF) [1]. Based on the information provided by these authors, we suggest that some of the host-related factors may have been responsible for dissemination of the dengue virus (DENV) infection in the 41-year-old female patient. In a study on ethnic Thais with secondary infections [2], a variety of HLA class I alleles (HLA-A 0203, 0207, A11, B 15, B 44, B 46, B 48, B 51, B 52), DC-SIGN promoter polymorphisms, and the AB blood group were found to be independently associated with either a susceptibility or resistance to dengue fever (DF) and the more severe DHF. Furthermore, the allelic variants of multiple gene loci involved in both acquired and innate immune responses were found to contribute significantly to DENV disease outcome and severity [2].

The failure of the authors from Cuba to collect blood samples for transmission electron microscopy (TEM) studies [1] was unfortunate as such studies would have revealed the events occurring during the interaction between DENV and platelets. In a study by Ghosh et al. [3], an in vitro exposure of platelets from healthy donors to a cell culture-adapted dengue 2 virus isolate was associated with platelet activation, an increased P-selectin expression, and fibrinogen-binding property. The images obtained with atomic force microscopy, electron microscopy, and flowcytometry indicated an altered platelet membrane

S. C. Arya $(\bowtie) \cdot$ N. Agarwal

Sant Parmanand Hospital, Delhi 110054, India

e-mail: subhashbhapaji@gmail.com; subhashji@hotmail.com architecture, degranulation, presence of filo podia, and dilatation of the open canalicular system [3].

Last but not least, it would also be possible to detect the precise localization of DENV RNA by in situ PCR analyses on paraffin-embedded tissues that had been stored, as such analyses would leave the tissue architecture intact. Localization of DENV RNA would be easier in postmortem tissues and in tissues obtained by percutaneous needle biopsy. In a study by Kangwanpong et al. [4], tissues from an 11-year-old Thai boy who died with the clinical diagnosis of DHF were treated by transcribing the viral RNA to DNA, followed by amplification using PCR and subsequent in situ hybridization. DENV RNA of the infected boy was detected in hepatocytes in the mid-zonal region of the liver; scattered macrophages were also observed in the skin and lymph nodes [4].

Conflict of interest None.

\section{References}

1. Limonta D, Falcón V, Torres G, Capó V, Menéndez I, Rosario D, Castellanos Y, Alvarez M, Rodríguez-Roche R, de la Rosa MC, Pavón A, López L, González K, Guillén G, Diaz J, Guzmán MG. Dengue virus identification by transmission electron microscopy and molecular methods in fatal dengue hemorrhagic fever. Infection. 2012; 40:689-94. doi:10.1007/s15010-012-0260-7.

2. Stephens HA. HLA and other gene associations with dengue disease severity. Curr Top Microbiol Immunol. 2010;338:99-114.

3. Ghosh K, Gangodkar S, Jain P, Shetty S, Ramjee S, Poddar P, Basu A. Imaging the interaction between dengue 2 virus and human blood platelets using atomic force and electron microscopy. J Electron Microsc (Tokyo) 2008;57:113-8.

4. Kangwanpong D, Bhamarapravati N, Lucia HL. Diagnosing dengue virus infection in archived autopsy tissues by means of the in situ PCR method: a case report. Clin Diagn Virol. 1995;3:165-72. 